\title{
Cyclic Citrullinated Peptide Antibody
}

National Cancer Institute

\section{Source}

National Cancer Institute. Cyclic Citrullinated Peptide Antibody. NCI Thesaurus. Code C121326.

An autoantibody directed ag ainst peptides or proteins whose arginine residues have been enzymatically converted to citrulline. It is often associated with rheumatoid arthritis. 